Präv Gesundheitsf $2021 \cdot 16: 381$

https://doi.org/10.1007/s11553-021-00878-1

Online publiziert: 9. Juli 2021

(c) Der/die Autor(en) 2021

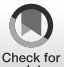

Daniela Borchart (D) - Hans Martin Hasselhorn - Jean-Baptist du Prel

Fachgebiet Arbeitswissenschaft, Bergische Universität Wuppertal, Wuppertal, Deutschland

\title{
Erratum zu: Zum Gesundheitsverhalten älterer Beschäftigter - inwieweit stimmen Selbsteinschätzung und Realität überein?
}

zenz steht und die betreffende Handlung nicht nach gesetzlichen Vorschriften erlaubt ist, ist für die oben aufgeführten Weiterverwendungen des Materials die Einwilligung des jeweiligen Rechteinhabers einzuholen.

Weitere Details zur Lizenz entnehmen Sie bitte der Lizenzinformation aufhttp:// creativecommons.org/licenses/by/4.0/ deed.de.

\section{Korrespondenzadresse}

Daniela Borchart, M. Sc.

Fachgebiet Arbeitswissenschaft, Bergische Universität Wuppertal

Gaußstraße 20, 42119 Wuppertal, Deutschland borchart@uni-wuppertal.de

Das Urheberrecht des Artikels wurde deshalb in (c) Der/die Autor(en) 2020 geändert.

Dieser Artikel ist jetzt unter der Creative Commons Namensnennung 4.0 International Lizenz veröffentlicht, welche die Nutzung, Vervielfältigung, Bearbeitung, Verbreitung und Wiedergabe in jeglichem Medium und Format erlaubt, sofern Sie den/die ursprünglichen Autor(en) und die Quelle ordnungsgemäß nennen, einen Link zur Creative Commons Lizenz beifügen und angeben, $\mathrm{ob}$ Änderungen vorgenommen wurden.

Die in diesem Artikel enthaltenen Bilder und sonstiges Drittmaterial unterliegen ebenfalls der genannten Creative Commons Lizenz, sofern sich aus der Abbildungslegende nichts anderes ergibt. Sofern das betreffende Material nicht unter der genannten Creative Commons Li-
Funding. Open Access funding enabled and organized by Projekt DEAL

Open Access. Dieser Artikel wird unter der Creative Commons Namensnennung 4.0 International Lizenz veröffentlicht, welche die Nutzung, Vervielfältigung, Bearbeitung, Verbreitung und Wiedergabe in jeglichem Medium und Format erlaubt, sofern Sie den/die ursprünglichen Autor(en) und die Quelle ordnungsgemäß nennen, einen Link zur Creative Commons Lizenz beifügen und angeben, ob Änderungen vorgenommen wurden.

Die in diesem Artikel enthaltenen Bilder und sonstiges Drittmaterial unterliegen ebenfalls der genannten Creative Commons Lizenz, sofern sich aus der Abbildungslegende nichts anderes ergibt. Sofern das betreffende Material nicht unter der genannten Creative Commons Lizenz steht und die betreffende Handlung nicht nach gesetzlichen Vorschriften erlaubt ist, ist für die oben aufgeführten Weiterverwendungen des Materials die Einwilligung des jeweiligen Rechteinhabers einzuholen.
Weitere Details zur Lizenz entnehmen Sie bitte der Lizenzinformation auf http://creativecommons.org/ licenses/by/4.0/deed.de.
Die Online-Version des Originalartikels ist unter https://doi.org/10.1007/s11553-020-00765-1 zu finden. 